\title{
The effect of conjugated linoleic acid supplementation on the nutritional status of COPD patients
}

This article was published in the following Dove Press journal:

International Journal of COPD

31 October 2016

Number of times this article has been viewed

Hassan Ghobadi

Somaieh Matin ${ }^{2}$

Ali Nemati ${ }^{3}$

Abbas Naghizadeh-baghi ${ }^{4}$

'Pulmonary Division, ${ }^{2}$ Internal Medicine Department, ${ }^{3}$ Biochemistry and Nutrition Department, ${ }^{4}$ Basic Sciences Department, Ardabil University of Medical Sciences, Ardabil, Iran
Correspondence: Somaieh Matin Internal Medicine Department. Ardabil University of Medical Sciences, Shahid Jeddi Street, Ardabil 5615783143, Iran

Tel +98453325 |40 |

Fax +98 $453325 \quad 1410$

Emailsmh.matin@yahoo.com
Background: COPD patients are susceptible to anorexia, reduction of caloric intake, weight loss, and malnutrition. One of the possible mechanisms is the increase of inflammatory markers such as interleukin $1 \beta\left(\mathrm{IL}_{1 \beta}\right)$, is highly correlated with anorexia. Considering the anti-inflammatory role of conjugated linoleic acid (CLA), this study aimed to investigate the effect of CLA supplementation on the nutritional status of COPD patients.

Patients and methods: In a double-blind clinical trial, 93 COPD patients who volunteered to participate in the study and who filled out a written consent form, were randomly assigned to control or supplementation groups. The patients in the supplementation group received $3.2 \mathrm{~g}$ of CLA on a daily basis for 6 weeks, while those in the control group received placebo on a daily basis for 6 weeks. For $\mathrm{IL}_{1 \beta}$ assessment, the patients' anthropometric indices and appetite score were checked and their blood samples were collected both before and after the treatment. Moreover, in order to investigate the changes in the caloric intake trend during the study, their dietary intake levels were assessed using 24-hour dietary recall, 3 days a week at the onset, in the 4th week, and at the end of the study. Eventually, 90 patients completed the study.

Results: The results demonstrated a significant increase in appetite score $(P=0.001)$, average caloric intake $(P=0.01)$, and macronutrient intake $(P<0.05)$, while a significant decrease was observed in the serum level of $\mathrm{IL}_{1 \beta}$ among the patients of the supplementation group $(P=0.008)$. Meanwhile, although the supplementation group's body mass index was also higher on completion, compared to their own initial state as well as to that in the control group, the differences were not significant $(P=0.13)$.

Conclusion: The findings of this research indicate that the consumption of CLA supplementation can be effective in regulating the appetite and improving the nutritional status of patients suffering from COPD through adjusting the serum level of $\mathrm{IL}_{1 \beta}$.

Keywords: COPD, CLA, appetite, nutritional status, $\mathrm{IL}_{1 \beta}$

\section{Introduction}

COPD is a common respiratory condition, which occurs with pulmonary and extrapulmonary complications, accompanied by systemic inflammations and is characterized by irreversible airflow limitations. ${ }^{1}$ It has been predicted that by 2020 , it would be the third most common cause of death and the fifth most common cause of disability worldwide. ${ }^{2}$ Smoking and factors such as contamination of the workplace, environmental pollution, and genetics are found to be the main causes of this disease. ${ }^{3,4}$

Extrapulmonary complications that occur in COPD patients are appetite reduction, decrease of caloric intake, and malnutrition..$^{5}$ Malnutrition leads to increased risks of 
mortality among these patients. ${ }^{6}$ The increase of inflammatory factors such as serum level of C-reactive protein ${ }^{7}$ and inflammatory interleukins (ILs) such as $\mathrm{IL}_{1 \beta}, \mathrm{IL}_{6}$, and also tumor necrosis factor- $\alpha$ has been found to be among the possible causes of malnutrition. ${ }^{8}$ In various studies, the increase in the serum level of ILs such as $\mathrm{IL}_{1 \beta}$ and $\mathrm{IL}_{6}$ as well as tumor necrosis factor- $\alpha$ has been reported in these patients. ${ }^{9-11}$ The increase of $\mathrm{IL}_{1 \beta}$ strongly causes anorexia, increased energy consumption, loss of muscle protein, and leptin release of adipose cells, which, in turn, lead to malnutrition. ${ }^{12,13}$

The use of dietary supplements is usually recommended for the treatment of malnutrition after COPD diagnosis, and it has been reported that the nutritional supplementations can improve nutritional status, anthropometric factors, and body weight, ${ }^{14,15}$ reduce disease symptoms, ${ }^{16}$ and improve quality of life. ${ }^{17}$

One of the supplements used along with treatment is conjugated linoleic acid (CLA; polyunsaturated fatty acid), which is naturally found in animal sources. ${ }^{18}$ In recent years, increasing attention has been paid to the beneficial effects of CLA on individuals' health status. ${ }^{19}$ To mention a few findings, researchers have discovered that it improves food sufficiency, energy metabolism, ${ }^{20}$ and anti-inflammatory properties. $^{21}$ The effect of CLA on some of the inflammatory factors has been demonstrated in previous studies $;{ }^{21}$ however, scant studies have examined its effect on the nutritional status and caloric intake of COPD patients. Therefore, this study aimed to evaluate the effects of CLA supplementation on the nutritional status of COPD patients.

\section{Patients and methods Study design and population}

Ninety-three male COPD patients were studied in a doubleblind clinical trial at the pulmonary ward of the Imam Khomeini Hospital in Ardabil in April-December 2015. To do so, the patients suffering from COPD were selected based on the American Thoracic Society criteria. ${ }^{22}$ The selected patients had chronic cough, sputum production, and dyspnea with the spirometry results of forced expiratory volume at first second/forced vital capacity ratio $<70 \%$, and their age range was $40-80$ years. The COPD patients suffering from other chronic diseases such as cardiovascular diseases, diabetes, and malignancies were excluded from the study. Before the study, all the participants signed an informed consent and completed a reliable and validated questionnaire, which was designed to gather anthropometric and demographic information. The information obtained through the questionnaires contained each participant's name, age, literacy level, job, address, history of smoking and quitting it, and the number of exacerbations experienced in the previous year. Eventually, 90 patients accomplished the study (45 patients in each of the placebo and supplementation groups) (Figure 1).

This study was ratified in the research department of Ardabil University of Medical Sciences (Iran) with the ethical code of "Arums.REC.93.56" and registered in Iranian Registry of Clinical Trial with the code of "IRCT2015080823559N1".

\section{Anthropometric information}

The patients' weight and height indices were recorded, and their body mass indices (BMIs) were obtained by calculating the ratio of their weight $(\mathrm{kg})$ to their height squared $\left(\mathrm{m}^{2}\right)$ at the beginning and at the sixth week of the study. The individuals' fasting weights were measured with the accuracy of $0.1 \mathrm{~kg}$ using Seca scales while they were without shoes and had light clothes on. Each time at certain stages, accuracy and precision of the Seca scales were calibrated using a standard $5 \mathrm{~kg}$ weight. Moreover, the height of the participants was measured by a graded wall. To do so, a measuring tape was installed on the wall. The participants stood upright while their heels, buttocks, shoulders, and heads leaned on the wall. Then, by placing a ruler horizontally on their head, their height was measured with the accuracy of $1 \mathrm{~cm}$.

\section{Nutritional information}

The patients' nutritional intake levels were assessed using a 24-hour dietary recall 3 days a week (2 weekdays and 1 weekend day) at the beginning, at the 4 th week, and at the 6 th week of the study (nine times in total). The content of the nutrients (macronutrients and micronutrients) and the energy intake of the patients were measured and analyzed by the Nutritionist IV software. A standard form was used to determine the appetite score of the participants at the beginning, at the fourth week, and at the sixth week of the study.

\section{Biochemical information}

Information on biochemical parameters of the patients' blood: 3 cc of venous blood sample was taken from each of the patients with 12 hours of fasting at the beginning and at the end of the study. The samples were gently transferred to test tubes, labeled, and then taken to a laboratory for serum separation. They were centrifuged at 4,000 rpm for 5 minutes and then poured into microtubes for $\mathrm{IL}_{1 \beta}$ test. The tubes were transferred to a refrigerator with the temperature of $-80^{\circ} \mathrm{C}$. $\mathrm{IL}_{1 \beta}$ was measured with enzyme-linked 


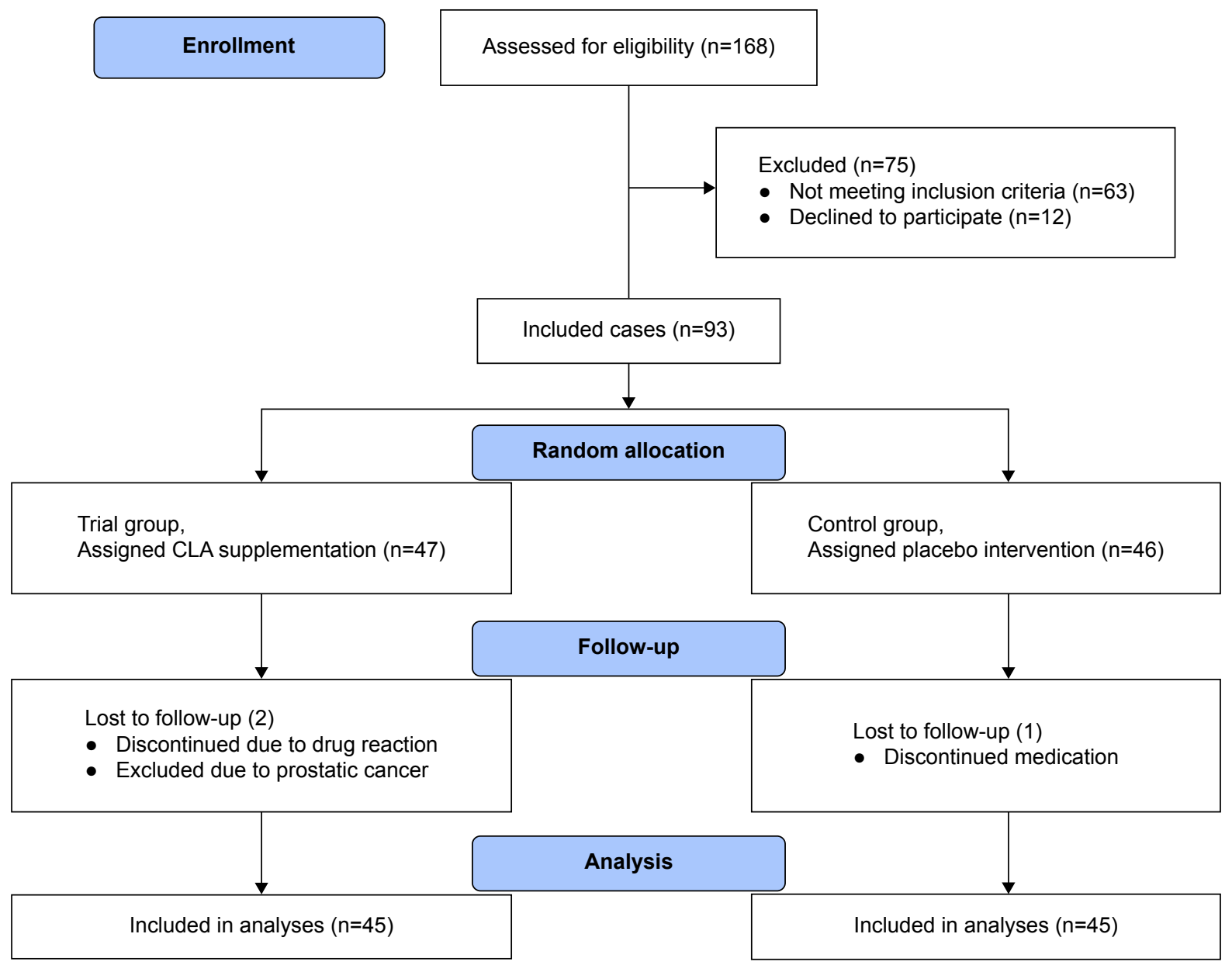

Figure I The effect of CLA supplementation on the nutritional status of COPD patients flow diagram. Abbreviation: CLA, conjugated linoleic acid.

immunosorbent assay (ELISA) method using a kit produced by the German company of Zelbio. According to the instructions of the manufacturer of the kit, $\mathrm{IL}_{1 \beta}$ was diluted one in ten. In order to increase the accuracy of the results, double samples were analyzed in 96-well ELISA plates using the standard protocol. Then, the colors formed at the frequencies of $450 \mathrm{~nm}$ and $630 \mathrm{~nm}$ were identified by "Anhos 2000 microplate reader", and the concentration of the blood samples was calculated by Multicalc (Wallac, Turku, Finland) software.

\section{Supplementation}

The supplementation group received a daily amount of $3.2 \mathrm{~g}$ CLA soft gel (with 80\% purity, which includes c9-t11 and c12-t10 isomers (50/50) and is manufactured in the form of tablets in the US with the commercial name of Nutrex), while the control group received the same amount of placebo for 6 weeks. Before the beginning of the study, the boxes containing CLA and placebo were coded as A and B, so that the researchers and the patients cannot identify the kind of supplementation offered to each group and so that the study can be conducted in a double-blinded manner.

\section{Patients' follow-up}

During the study, the patients were called every week to obviate any problems that might arise for them as well as to ensure that they take the supplementation. In order to both control the consumption of supplementation and prevent the loss of samples, the follow-up was also done through faceto-face visits, in addition to making telephone calls. The pills needed for 6 weeks were distributed to the patients and they were reminded that they should return the rest of the pills if they stop consuming them. Ninety-six percent of the patients took the pills regularly and were, therefore, investigated during the study. The patients' compliance with the consumption of the pills was evaluated by the remaining pills at the end of the sixth week. The patients were informed about the possible complications of the pills, and the telephone number 
of the researcher was given to them to report any problems they might encounter during the study.

\section{Data analysis}

Kolmogorov-Smirnov test was employed to investigate the normality of the distribution of data for each variable. The results obtained from them were analyzed by SPSS V11 software, and $t$-test, chi-square test, and analysis of variance were employed to determine the relationship between the variables. Significance level was taken to be 0.05 for all the tests. In addition, wherever possible, the results were expressed in the form of deviations $( \pm)$ from the mean.

\section{Results}

There was no significant difference between the two groups in terms of their average age, smoking history, forced expiratory volume at first second (Table 1), weight, height, and BMI at the beginning of the study (Table 2). Paired $t$-test showed that the average BMI of the patients in the supplementation group increased during the study, but it was not statistically significant $(P=0.13)$.

The results showed that, at the beginning of the study, there was no significant difference between the two groups in their serum level of $\mathrm{IL}_{1 \beta}$; however, at the end of the study, the difference appeared to be significant $(P=0.02)$. Paired $t$-test revealed that in the supplementation group, the serum level of $\mathrm{IL}_{1 \beta}$ decreased significantly in the sixth week compared to the beginning of the study $(P=0.008)$, while in the placebo group, it increased significantly during the same time ( $P=0.02$; Table 3$)$.

According to the results, at the beginning of the study, there was not any significant difference between the patients of the two groups in their appetite score and the average caloric intake. Yet, this difference was found to be statistically significant at the end of the study as the results of independent $t$-test revealed $(P<0.05)$.

Furthermore, the analyses showed that although the difference in the appetite score of the patients in the

Table I Demographic and clinical parameters of lung function in the supplementation and placebo groups

\begin{tabular}{lllll}
\hline Parameters & $\begin{array}{l}\text { Supplementation } \\
\text { group }\end{array}$ & $\begin{array}{l}\text { Placebo } \\
\text { group }\end{array}$ & \multirow{2}{\text{P-value}^{\mathbf{a}}}{} \\
\cline { 2 - 2 } & Values (n=45) & & Values (n=45) \\
\hline Age (years) & $63.60 \pm 10.94$ & & $61.64 \pm 10.60$ & 0.39 \\
Smoking (packs/year) & $42.80 \pm 23.84$ & & $44.89 \pm 25.43$ & 0.68 \\
FEV \% predicted & $47.83 \pm 18.01$ & & $42.89 \pm 14.82$ & 0.06 \\
\hline
\end{tabular}

Notes: The data are presented as mean \pm SD. alndependent-sample $t$-test significant difference between groups. supplementation group was not significant in the fourth week ( $P=0.07)$, it was significant in the sixth week $(P=0.001)$ as compared to the beginning of the study. As for the placebo group, the overall changes throughout the study were not found to be statistically significant ( $P=0.06$; Figure 2 ).

In addition, repeated measures analysis of variance demonstrated a significant increase in the average caloric intake of the patients in the supplementation group during the study $(P=0.01)$. As regards this variable, the difference observed between the fourth week and the beginning of the study was not significant $(P=0.06)$, while the difference between the end of the sixth week and the beginning of the study as well as between the end of the sixth week and the fourth week appeared to be significant $(P<0.05)$. In the placebo group, the average changes throughout the study were not found to be statistically significant (Figure 3).

The results revealed that the average amount of carbohydrate, protein, fat, fatty acids (saturated, unsaturated with one double bond, and polyunsaturated), cholesterol, and fiber intake was not significantly different between the two groups at the beginning of the study, but, at the end of the study, the results of independent $t$-test revealed that the difference between carbohydrate, protein, fat, fatty acids (saturated, unsaturated with one double bond, and polyunsaturated), cholesterol, and fiber intake is significant $(P<0.05)$.

In addition, repeated measures analysis of variance demonstrated a significant increase in the average carbohydrate, protein, and fat intake $(P<0.05)$ in the supplementation group during the study; the changes observed during the study in the average intake of fatty acids (saturated, unsaturated with one double bond, and polyunsaturated), cholesterol, and fiber were not significant. In the placebo group, the trend in carbohydrate and protein intake showed significant decrease during the study $(P<0.05$; Table 4$)$.

For both the groups under study, the analysis through post hoc least significant difference test did not show any significant differences in the average fatty acids (saturated, unsaturated with one double bond, and polyunsaturated), cholesterol, and fiber intake neither in the fourth week nor in the sixth week compared to the beginning of the study. Similarly, in the placebo group, the decrease in the intake of these during the study was not significant (Table 4).

Regarding the average serum electrolytes intake, the results did not show any significant difference between the two groups at the beginning of the study. In addition, at the end of the study, significant differences between the two groups were only observed in the average calcium, potassium, and selenium intake $(P=0.04$; Table 5$)$. 
Table 2 The average amount of weight, height, and BMI in supplementation and control groups

\begin{tabular}{|c|c|c|c|c|}
\hline Variables & Measurement stage & Supplementation group $(n=45)$ & Placebo group $(n=45)$ & $P$-value ${ }^{a}$ \\
\hline \multirow[t]{2}{*}{ Weight (kg) } & At baseline & $67 \pm 4.6$ & $68.33 \pm 4.3$ & 0.42 \\
\hline & On completion & $67.18 \pm 3.3$ & $68 \pm 3.7$ & 0.25 \\
\hline$P$-value ${ }^{b}$ & & 0.07 & 0.07 & \\
\hline \multirow[t]{2}{*}{ BMI $\left(\mathrm{kg} / \mathrm{m}^{2}\right)$} & At baseline & $24.91 \pm 3.54$ & $24.84 \pm 2.96$ & 0.42 \\
\hline & On completion & $24.97 \pm 3.34$ & $24.74 \pm 3.06$ & 0.25 \\
\hline$P$-value ${ }^{b}$ & & 0.13 & 0.2 & \\
\hline Height (cm) & At baseline & $164.13 \pm 10$ & $166 \pm 8$ & 0.46 \\
\hline
\end{tabular}

Notes: andependent-sample $t$-test significant difference in the 6th week between groups. ${ }^{\text {bPaired }} t$-test significant difference at the beginning and the end of the study in each group. Data are presented as mean \pm SD.

Abbreviations: BMI, body mass index; SD, standard deviation.

Based on the obtained results, there was no significant difference between the two groups in their average vitamin intake at the beginning of the study. Furthermore, at the end of the study, significant differences between them were only observed in vitamins $\mathrm{B} 2, \mathrm{~B} 6$, and $\mathrm{E}$ intake $(P<0.05)$. In addition, in the supplementation group, only average vitamins B2, B6, and E intake increased significantly during the study $(P=0.02$; Table 6$)$.

\section{Discussion}

Studies investigating the effect of CLA on COPD patients are scant. To the best knowledge of the researchers, this study is the first one addressing this issue. As for other diseases, a number of studies have been conducted investigating the effect of this supplement on healthy people, chronic diseases, and different types of cancers some of which are discussed briefly later.

This study demonstrated that the consumption of CLA reduces the serum level of $\mathrm{IL}_{1 \beta}$ in COPD patients. Several other studies have shown that some cytokines such as serum $\mathrm{IL}_{1 \beta}$ increase in these patients. ${ }^{9,11}$

Sapey et $\mathrm{al}^{23}$ indicated that the serum level of $\mathrm{IL}_{1 \beta}$ is strongly related to COPD disease severity. Hammad et al ${ }^{24}$ found that there is a strong significant relationship between COPD severity and serum level of $\mathrm{IL}_{1 \beta}$, which shows that it plays an important role in the process of systemic inflammation experienced by the COPD patients. In their casecontrol study, Hegab et $\mathrm{al}^{25}$ found that the serum level of
$\mathrm{IL}_{1 \beta}$ in COPD patients is considerably higher than that in the healthy people, which indicates that $\mathrm{IL}_{1 \beta}$ is involved in the pathogenesis of COPD. In their study, DeBoer et $\mathrm{al}^{26}$ injected $\mathrm{IL}_{1 \beta}$ into mice and observed that after 3-12 hours, nutritional intake significantly decreased. Therefore, they concluded that $\mathrm{IL}_{1 \beta}$ is one of the important mediators in this process. It is one of the pre-inflammatory cytokines, which is produced from activated macrophages, and is one of the important mediators of inflammatory response, which causes expression and demonstration of many genes. ${ }^{13,26}$ The increase of this inflammatory mediator in COPD patients causes appetite reduction, which contributes to weight loss, and reduction of BMI, which, in turn, leads to increased risks of malnutrition. ${ }^{12,27}$ CLA supplementation with different isomer percentages and sometimes a relatively special isomer is considered as an agent that is antioxidant, antiinflammatory, anti-obesity, anticancer, anti-atherosclerosis, stimulator of immune system, stimulator of growth factor, changer of body composition from fat to muscle, etc, in animal and human models. ${ }^{28,29}$ With its anti-inflammatory properties, it can also inhibit inflammatory mediators such as $\mathrm{IL}_{1 \beta}$ and decrease their serum level and, thereby, lead to appetite improvement in patients. ${ }^{18,20}$

The findings of this study are in line with those of the study of Wendell et al..$^{30}$ They showed that long-term consumption of CLA could reduce inflammatory mediators such as $\mathrm{IL}_{1 \beta}$, which exacerbate disease, though it should be noted that their study was conducted on asthma patients.

Table 3 The average amount of $\mathrm{IL}_{\mid \beta}$ serum level in the supplementation and control groups

\begin{tabular}{lllll}
\hline Variables & Measurement stage & Supplementation group $(\mathrm{n}=45)$ & Placebo group $(\mathrm{n}=\mathbf{4 5})^{P}$ & $\mathbf{P}$-value \\
\hline $\mathrm{IL}_{1 \beta}(\mathrm{ng} / \mathrm{mL})$ & At the beginning & $6.38 \pm 1.95$ & $6.27 \pm 1.02$ & 0.72 \\
& At the end & $5.61 \pm 0.93$ & $6.60 \pm 1.07$ & $0.02^{\mathrm{a}}$ \\
P-value $^{\mathrm{b}}$ & & $0.008^{\mathrm{b}}$ & $0.025^{\mathrm{b}}$ & \\
\hline
\end{tabular}

Notes: andependent-sample $t$-test significant difference in the sixth week between groups. ${ }^{\text {PPaired }} t$-test significant difference at the beginning and the end of the study in each group. Data are presented as mean \pm SD.

Abbreviations: $\mathrm{IL}_{1 \beta}$, interleukin I $\beta$; SD, standard deviation. 


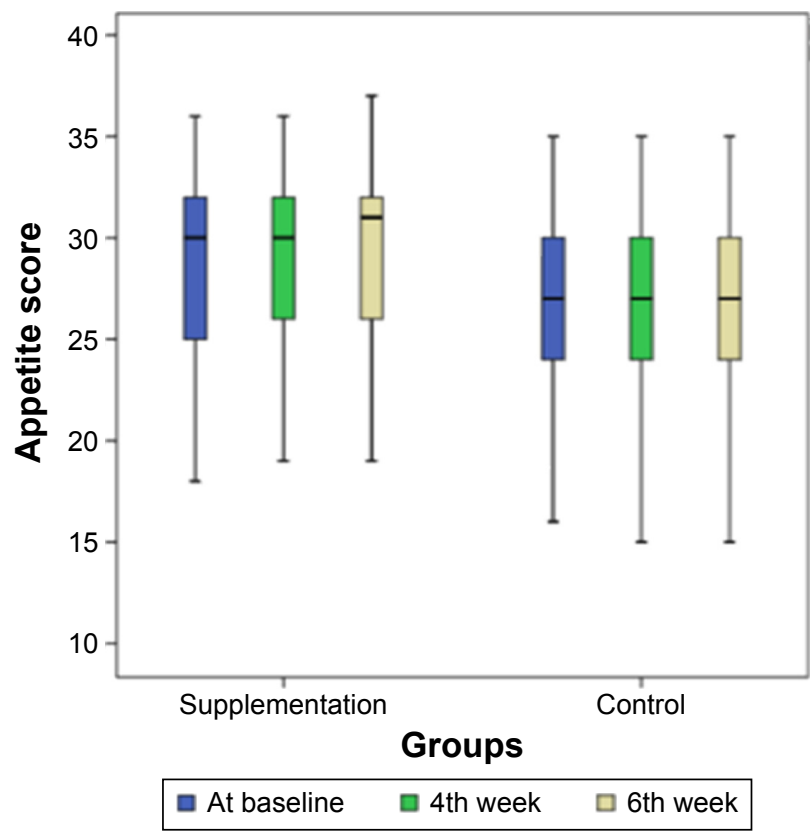

Figure 2 Charts demonstrating the trend of CNAQ score ${ }^{37}$ changes during the study in supplementation and control groups.

Note: Patient's appetite scores at the beginning (blue), 4th week (green), and 6th week (milky) chart.

Abbreviation: CNAQ, Council of Nutrition Appetite Questionnaire.

The findings were not in concordance with those reported by Kelly ${ }^{31}$ and Tavakkoli Darestani et al. ${ }^{32}$ In their studies, the consumption of CLA supplementation by healthy females did not affect the serum level of $\mathrm{IL}_{1 \beta}$, which might be related to the sample they studied. In this study, however, the use

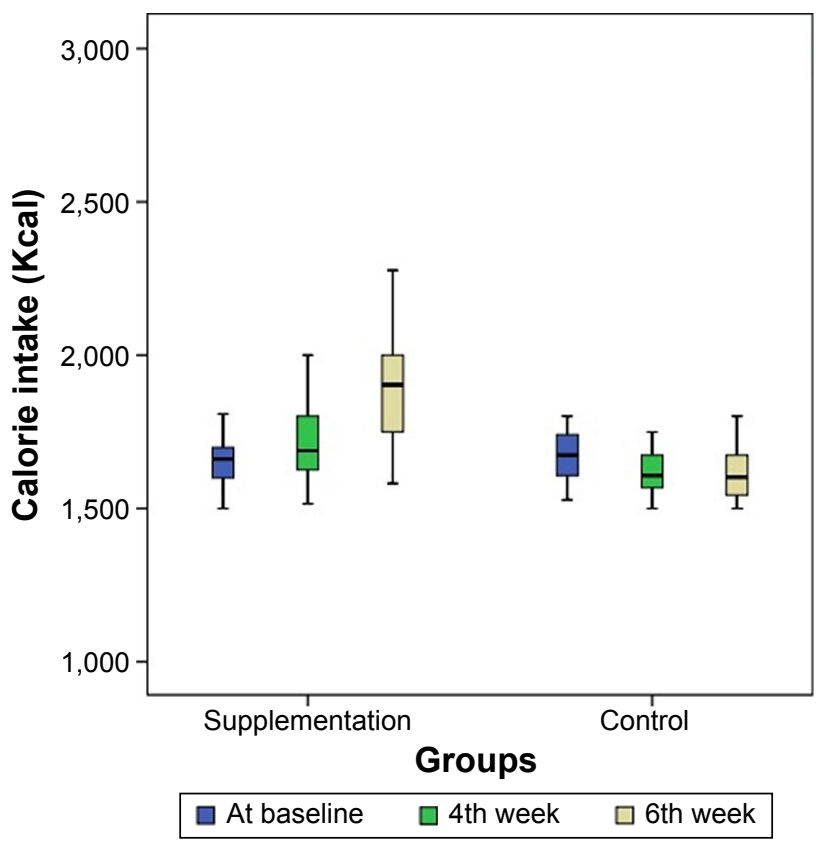

Figure 3 Charts demonstrating the trend of calorie intake changes during the study in supplementation and control groups.

Note: Patient's calorie intake at the beginning (blue), 4th week (green), and 6th week (milky) chart. of CLA supplementation for 6 weeks significantly increased caloric intake and the absorption of macronutrients, such as carbohydrate, fat and protein, in the patients, which lead to an increase in their weight and BMI. However, the changes were not found to be statistically significant, one reason for which seems to be the limited intervention time.

Zambell et $\mathrm{al}^{33}$ realized that the consumption of CLA by young females for 64 days significantly increased their caloric intake.

Although the mechanism of action of CLA is not exactly known, one of the many possible mechanisms proposed in this regard is that, through changing the composition of cell membrane phospholipids, they can alter the cell membrane functions such as secondary messages, neurotransmitter receptors, and transport proteins and inhibit the production of preinflammatory cytokines. ${ }^{34}$ Changes in membrane phospholipids as well as the regulation of cytokines production might affect the synthesis of neuropeptides related to nutritional intake and eventually lead to the improvement of anorexia, which, in turn, can improve patients' nutritional status and prevent weight loss that causes mortality to increase among COPD patients. ${ }^{35}$

One of the limitations of this study was the limitation that the researchers encountered in the process of identifying patients compatible with the criteria for entering this study. Another limitation was that, due to the lack of financial resources, the level of linoleic acid in the patients' blood was not checked. Limitations in financial resources that did not allow the investigation of the levels of other effective inflammatory cytokines and the use of drugs for longer periods of time as well as the lack of similar studies about the effect of CLA on this disease made it impossible to compare the results of this study with other similar ones. Therefore, the authors had to refer to the studies conducted on other chronic diseases.

\section{Conclusion}

In this study, CLA supplementation, in addition to significantly reducing the serum level of $\mathrm{IL}_{1 \beta}$, increased appetite score, average caloric intake, and average macronutrients intake in COPD patients. Considering the findings of this study, it can be concluded that CLA supplementation increases appetite and nutritional intake and improves nutritional status of COPD patients, which, in turn, lead to decrease in malnutrition, slow progression of the disease, and may reduce the mortality.

\section{Acknowledgments}

This article is extracted from the Internal Medicine thesis, Ardabil University of Medical Science, Iran. ${ }^{36}$ The authors would like to thank all the patients who participated in this study. 
Table 4 The average amount of macroelements intake between the supplementation and control groups

\begin{tabular}{|c|c|c|c|c|}
\hline Variables & Measurement stage & Supplementation group $(n=45)$ & Control group $(n=45)$ & $P$-value \\
\hline \multirow[t]{3}{*}{ Carbohydrate (g/d) } & At baseline & $489.13 \pm 51.67$ & $467.20 \pm 53.13$ & 0.14 \\
\hline & 4th week & $469.20 \pm 41.92$ & $423.0 \pm 48.1$ & 0.92 \\
\hline & 6th week & $503.0 \pm 42.98$ & $401.93 \pm 47.97$ & $0.03^{\mathrm{a}}$ \\
\hline$P$-value & & $0.03^{b}$ & $0.00 \mathrm{I}^{\mathrm{b}}$ & \\
\hline \multirow[t]{3}{*}{ Protein (g/d) } & At baseline & $91.47 \pm 4.30$ & $89.93 \pm 19.52$ & 0.08 \\
\hline & 4th week & $91.50 \pm 4.20$ & $79.73 \pm 16.43$ & $0.02^{\mathrm{a}}$ \\
\hline & 6th week & $110.50 \pm 2.80$ & $47.33 \pm 17.17$ & $0.0 \mathrm{I}^{\mathrm{a}}$ \\
\hline$P$-value & & $0.00 I^{b}$ & $0.06^{\mathrm{b}}$ & \\
\hline \multirow[t]{3}{*}{ Total fat $(g / d)$} & At baseline & $49.60 \pm \mid 1.21$ & $49.80 \pm 16.45$ & 0.81 \\
\hline & 4th week & $47.82 \pm 10.96$ & $46.46 \pm 9.77$ & 0.16 \\
\hline & 6th week & $50.98 \pm \mid 1.21$ & $40.20 \pm \mid 1.91$ & $0.0 \mathrm{I}^{\mathrm{a}}$ \\
\hline$P$-value & & $0.04^{b}$ & 0.5 & \\
\hline \multirow[t]{3}{*}{ Saturated fat (g/d) } & At baseline & $9 \pm 3$ & $11 \pm 6$ & 0.71 \\
\hline & 4th week & $10 \pm 5$ & $10 \pm 4$ & 0.58 \\
\hline & 6th week & $12 \pm 4$ & $9 \pm 3$ & $0.04^{\mathrm{a}}$ \\
\hline$P$-value & & 0.34 & 0.18 & \\
\hline \multirow[t]{3}{*}{ Mono unsaturated fat $(\mathrm{g} / \mathrm{d})$} & At baseline & $12 \pm 4$ & $12.2 \pm 4.5$ & 0.06 \\
\hline & 4th week & $14 \pm 5$ & $\mathrm{II} \pm 4$ & 0.8 \\
\hline & 6th week & $15 \pm 4$ & $10.6 \pm 4$ & $0.03^{\mathrm{a}}$ \\
\hline$P$-value & & 0.19 & 0.39 & \\
\hline \multirow[t]{3}{*}{ Poly unsaturated fat (g/d) } & At baseline & $6 \pm 2$ & $6 \pm 3$ & 0.07 \\
\hline & 4th week & $6 \pm 2$ & $5 \pm 1.7$ & 0.49 \\
\hline & 6th week & $7 \pm 3$ & $5 \pm 2$ & $0.02^{\mathrm{a}}$ \\
\hline$P$-value & & 0.26 & 0.43 & \\
\hline \multirow[t]{3}{*}{ Cholesterol (mg/d) } & At baseline & $198 \pm 130$ & $172 \pm 120$ & 0.08 \\
\hline & 4th week & $234 \pm 115$ & $145 \pm 52$ & 0.03 \\
\hline & 6th week & $274 \pm 208$ & $131 \pm 39$ & $0.0 \mathrm{I}^{\mathrm{a}}$ \\
\hline$P$-value & & 0.58 & 0.42 & \\
\hline \multirow[t]{3}{*}{ Fiber $(g / d)$} & At baseline & $7 \pm 4$ & $6 \pm 2$ & 0.27 \\
\hline & 4th week & $7 \pm 1$ & $6 \pm 2$ & 0.38 \\
\hline & 6th week & $8 \pm 3$ & $5 \pm 2$ & $0.02^{\mathrm{a}}$ \\
\hline$P$-value & & 0.65 & 0.26 & \\
\hline
\end{tabular}

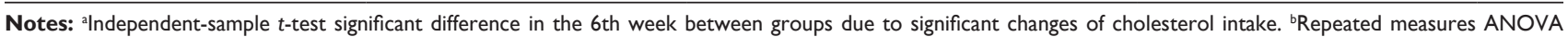
significant difference in the supplementation and placebo groups. Data are presented as mean \pm SD.

Abbreviations: ANOVA, analysis of variance; SD, standard deviation.

Table 5 The average amount of electrolytes intake $(\mathrm{mg})$ in the supplementation and placebo groups

\begin{tabular}{|c|c|c|c|c|}
\hline Variables & Measurement stage & Supplementation group $(n=45)$ & Placebo group $(n=45)$ & $P$-value \\
\hline \multirow[t]{3}{*}{$\mathrm{Na}$} & At baseline & $1,792 \pm 692$ & $\mathrm{I}, 854 \pm 676$ & $>0.05$ \\
\hline & 4th week & $1,619 \pm 573$ & $\mathrm{I}, 729 \pm 573$ & \\
\hline & 6th week & $\mathrm{I}, 694 \pm 40 \mathrm{I}$ & $\mathrm{I}, 694 \pm 40 \mathrm{I}$ & \\
\hline \multirow[t]{3}{*}{$\mathrm{Mg}$} & At baseline & $180 \pm 87$ & $196 \pm 87$ & $>0.05$ \\
\hline & 4th week & $194 \pm 92$ & $187 \pm 92$ & \\
\hline & 6th week & $193 \pm 87$ & $176 \pm 87$ & \\
\hline \multirow[t]{3}{*}{ K } & At baseline & $1,599 \pm 54$ & $\mathrm{I}, 702 \pm 54$ & $<0.05^{\mathrm{a}},<0.05^{\mathrm{b}}$ \\
\hline & 4th week & $1,703 \pm 67$ & $|, 698 \pm 7|$ & \\
\hline & 6th week & $\mathrm{I}, 750 \pm 78$ & $\mathrm{I}, 703 \pm 73$ & \\
\hline \multirow[t]{3}{*}{$\mathrm{Ca}$} & At baseline & $954 \pm 78$ & $914 \pm 82$ & $<0.05^{\mathrm{a}},<0.05^{\mathrm{b}}$ \\
\hline & 4th week & $984 \pm 73$ & $965 \pm 56$ & \\
\hline & 6th week & $1,003 \pm 68$ & $973 \pm 48$ & \\
\hline \multirow[t]{3}{*}{$P$} & At baseline & $953 \pm 78$ & $878 \pm 68$ & $>0.05$ \\
\hline & 4th week & $944 \pm 71$ & $980 \pm 67$ & \\
\hline & 6th week & $860 \pm 68$ & $860 \pm 54$ & \\
\hline \multirow[t]{3}{*}{$\mathrm{Fe}$} & At baseline & $37 \pm 4$ & $38 \pm 4$ & $>0.05$ \\
\hline & 4th week & $35 \pm 3$ & $39 \pm 3$ & \\
\hline & 6th week & $36 \pm 8$ & $42 \pm 8$ & \\
\hline
\end{tabular}


Table 5 (Continued)

\begin{tabular}{|c|c|c|c|c|}
\hline Variables & Measurement stage & Supplementation group $(n=45)$ & Placebo group $(n=45)$ & $P$-value \\
\hline \multirow[t]{3}{*}{$\mathrm{Zn}$} & At baseline & $17 \pm 4$ & $16 \pm 4$ & $>0.05$ \\
\hline & 4th week & $18 \pm 7$ & $19 \pm 7$ & \\
\hline & 6th week & $18 \pm 8$ & $17 \pm 8$ & \\
\hline \multirow[t]{3}{*}{$M n$} & At baseline & $1.3 \pm 0.7$ & $1.7 \pm 0.4$ & $>0.05$ \\
\hline & 4th week & $1.5 \pm 0.8$ & $1.8 \pm 0.8$ & \\
\hline & 6th week & $1.5 \pm 0.8$ & $1.4 \pm 0.5$ & \\
\hline \multirow[t]{3}{*}{$\mathrm{Se}$} & At baseline & $0.02 \pm 0.01$ & $0.03 \pm 0.02$ & $<0.00 \mathrm{I}^{\mathrm{a}},<0.05^{\mathrm{b}}$ \\
\hline & 4th week & $0.02 \pm 0.01$ & $0.02 \pm 0.01$ & \\
\hline & 6th week & $0.01 \pm 0.01$ & $0.02 \pm 0.02$ & \\
\hline \multirow[t]{3}{*}{$\mathrm{Cr}$} & At baseline & $0.01 \pm 0.001$ & $0.03 \pm 0.001$ & $>0.05$ \\
\hline & 4th week & $0.02 \pm 0.001$ & $0.07 \pm 0.00 \mathrm{I}$ & \\
\hline & 6th week & $0.04 \pm 0.003$ & $0.05 \pm 0.003$ & \\
\hline \multirow[t]{3}{*}{ Мо } & At baseline & $45.43 \pm 12.01$ & $47.39 \pm 12.01$ & $>0.05$ \\
\hline & 4th week & $47.5 \pm 11.2$ & $48.6 \pm 10.2$ & \\
\hline & 6th week & $42.67 \pm|0.7|$ & $45.77 \pm|1.7|$ & \\
\hline
\end{tabular}

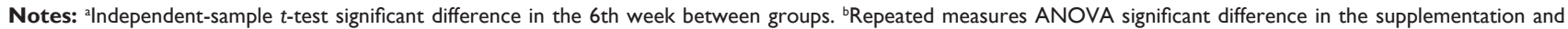
placebo groups. Data are presented as mean \pm SD.

Abbreviations: ANOVA, analysis of variance; SD, standard deviation.

Table 6 The average amount of vitamins intake in the supplementation and placebo groups

\begin{tabular}{|c|c|c|c|c|}
\hline Variables & Measurement stage & Supplementation group $(n=45)$ & Placebo group $(n=45)$ & $P$-value \\
\hline \multirow[t]{3}{*}{ VitBI (mg) } & At baseline & $0.98 \pm 0.87$ & $0.78 \pm 0.77$ & $>0.05$ \\
\hline & 4th week & $1.6 \pm 0.82$ & $0.69 \pm 0.82$ & \\
\hline & 6th week & $0.98 \pm 0.7$ & $0.78 \pm 0.7$ & \\
\hline \multirow[t]{3}{*}{ VitB3 (mg) } & At baseline & $17 \pm 9$ & $19 \pm 9$ & $>0.05$ \\
\hline & 4th week & $17 \pm 9.3$ & $19 \pm 9.3$ & \\
\hline & 6th week & $17 \pm 8.7$ & $18 \pm 8.7$ & \\
\hline \multirow[t]{3}{*}{ Folate $(\mu \mathrm{g})$} & At baseline & $59 \pm 54$ & $70 \pm 54$ & $>0.05$ \\
\hline & 4th week & $64 \pm 67$ & $74 \pm 7 \mid$ & \\
\hline & 6th week & $64 \pm 78$ & $70 \pm 73$ & \\
\hline \multirow{3}{*}{ VitC (mg) } & At baseline & $54 \pm 78$ & $74 \pm 82$ & $>0.05$ \\
\hline & 4th week & $84 \pm 73$ & $91 \pm 56$ & \\
\hline & 6th week & $87 \pm 68$ & $93 \pm 48$ & \\
\hline \multirow[t]{3}{*}{ VitB2 $(\mu \mathrm{g})$} & At baseline & $1.6 \pm 0.32$ & $1.4 \pm 0.32$ & $<0.05^{\mathrm{a}},<0.05^{\mathrm{b}}$ \\
\hline & 4th week & $1.6 \pm 0.34$ & $1.6 \pm 0.33$ & \\
\hline & 6th week & $1.6 \pm 0.32$ & $1.1 \pm 0.32$ & \\
\hline \multirow[t]{3}{*}{ VitB6 (mg) } & At baseline & $1.3 \pm 0.32$ & $\mathrm{I} .4 \pm 0.32$ & $<0.05^{\mathrm{a}},<0.05^{\mathrm{b}}$ \\
\hline & 4th week & $1.6 \pm 0.55$ & $1.6 \pm 0.17$ & \\
\hline & 6th week & $1.6 \pm 0.12$ & $1.5 \pm 0.32$ & \\
\hline \multirow[t]{3}{*}{ VitB I 2 (mg) } & At baseline & $4.3 \pm 0.7$ & $5.7 \pm 0.4$ & $>0.05$ \\
\hline & 4th week & $3.5 \pm 0.8$ & $4.8 \pm 0.8$ & \\
\hline & 6th week & $3.5 \pm 0.2$ & $4.4 \pm 0.5$ & \\
\hline \multirow[t]{3}{*}{ VitD $(\mu \mathrm{g})$} & At baseline & $32 \pm 0.7$ & $37 \pm 0.4$ & $>0.05$ \\
\hline & 4th week & $38 \pm 0.8$ & $38 \pm 0.8$ & \\
\hline & 6th week & $39 \pm 0.8$ & $38 \pm 0.5$ & \\
\hline \multirow[t]{3}{*}{ VitA $(\mu g)$} & At baseline & $459.43 \pm 52.01$ & $460.39 \pm 62.01$ & $>0.05$ \\
\hline & 4th week & $476 \pm 61.2$ & $458 \pm 50.2$ & \\
\hline & 6th week & $476 \pm 61.71$ & $457 \pm 61.71$ & \\
\hline \multirow[t]{3}{*}{ VitE (mg) } & At baseline & $14.43 \pm 12.0 \mid$ & $16.39 \pm 12.01$ & $<0.05^{\mathrm{a}},<0.05^{\mathrm{b}}$ \\
\hline & 4th week & $14.5 \pm 1 \mid .2$ & $15.6 \pm 10.2$ & \\
\hline & 6th week & $|5.67 \pm| 0.7 \mid$ & $|5.77 \pm||.7|$ & \\
\hline \multirow[t]{3}{*}{ Beta-carotene $(\mu \mathrm{g})$} & At baseline & $45.43 \pm 12.01$ & $47.39 \pm 12.01$ & $>0.05$ \\
\hline & 4th week & $47.5 \pm 11.2$ & $48.6 \pm 10.2$ & \\
\hline & 6th week & $42.67 \pm|0.7|$ & $45.77 \pm|| .7 \mid$ & \\
\hline
\end{tabular}

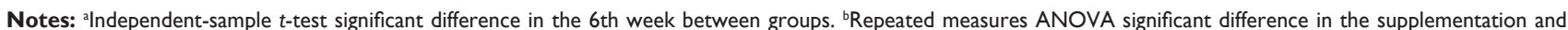
placebo groups. Data are presented as mean $\pm S D$.

Abbreviations: ANOVA, analysis of variance; SD, standard deviation. 


\section{Disclosure}

The authors report no conflicts of interest in this work.

\section{References}

1. Pauwels PRA, Rabe KF. Burden and clinical features of chronic obstructive pulmonary disease (COPD). Lancet. 2004;364(9434):613-620.

2. Viegi G, Scognamiglio A, Baldacci S, Pistelli F, Carrozzi L. Epidemiology of chronic obstructive pulmonary disease (COPD). Respiration. 2001;68(1):4-19.

3. Wang J, Spitz MR, Amos CI, Wilkinson AV, Wu X, Shete S. Mediating effects of smoking and chronic obstructive pulmonary disease on the relation between the CHRNA5-A3 genetic locus and lung cancer risk. Cancer. 2010;116(14):3458-3462.

4. Andersen ZJ, Hvidberg M, Jensen SS, et al. Chronic obstructive pulmonary disease and long-term exposure to traffic-related air pollution. Am J Respir Crit Care Med. 2011;183(4):455-461.

5. Engelen M, Schols A, Lamers A, Wouters E. Different patterns of chronic tissue wasting among patients with chronic obstructive pulmonary disease. Clin Nutr. 1999;18(5):275-280.

6. Ezzell L, Jensen GL. Malnutrition in chronic obstructive pulmonary disease. Am J Clin Nutr. 2000;72(6):1415-1416.

7. Argilés JM, Busquts S, Garcia-Martinez C, López-Soriano F. Mediators involved in the cancer anorexia-cachexia syndrome: past, present, and future. Nutrition. 2005;21(9):977-985.

8. Espat NJ, Moldawer LL, Copeland EM. Cytokine mediated alterations in host metabolism prevent nutritional repletion in cachectic cancer patients. J Clin Oncol. 1995;58(2):77-82.

9. Chung K. Cytokines in chronic obstructive pulmonary disease. Eur Respir J. 2001;18(34 suppl):50s-59s.

10. Chung K. Cytokines as targets in chronic obstructive pulmonary disease. Curr Drug Targets. 2006;7(6):675-681

11. Gan W, Man S, Senthilselvan A, Sin D. Association between chronic obstructive pulmonary disease and systemic inflammation: a systematic review and a meta-analysis. Thorax. 2004;59(7):574-580.

12. Argilés JM, López-Soriano FJ. Catabolic proinflammatory cytokines. Curr Opin Clin Nutr Metab Care. 1998;1(3):245-251.

13. Wagner PD. Possible mechanisms underlying the development of cachexia in COPD. Eur Respir J. 2008;31(3):492-501.

14. Collins PF, Stratton RJ, Elia M. Nutritional support in chronic obstructive pulmonary disease: a systematic review and meta-analysis. $\mathrm{Am} \mathrm{J}$ Clin Nutr. 2012;95(6):1385-1395.

15. Collins PF, Elia M, Stratton RJ. Nutritional support and functional capacity in chronic obstructive pulmonary disease: A systematic review and meta-analysis. Respirology. 2013;18(4):616-629.

16. Clini E, Ambrosino N. Nonpharmacological treatment and relief of symptoms in COPD. Eur Respir J. 2008;32(1):218-228.

17. Rüfenacht U, Ruhlin M, Wegmann M, Imoberdorf R, Ballmer P. Nutritional counseling improves quality of life and nutrient intake in hospitalized undernourished patients. Nutrition. 2010;26(1):53-60.

18. Steven W, Belury MA. Impact of conjugated linoleic acid on bone physiology: proposed mechanism involving inhibition of adipogenesis. Nutr Rev. 2011;69(3):123-131.

19. Bhattacharya A, Banu J, Rahman M, Causey J, Fernandes G. Biological effects of conjugated linoleic acids in health and disease. $J$ Nutr Biochem. 2006;17(12):789-810.

20. Nugent AP, Roche HM, Noone EJ, Long A, Kelleher DK, Gibney MJ. The effects of conjugated linoleic acid supplementation on immune function in healthy volunteers. Eur J Clin Nutr. 2005;59(6):742-750.
21. Yang $M$, Cook ME. Dietary conjugated linoleic acid decreased cachexia, macrophage tumor necrosis factor- $\alpha$ production, and modifies splenocyte cytokines production. Exp Biol Med. 2003;228(1):51-58.

22. Viegi G, Pedreschi M, Pistelli F, et al. Prevalence of airways obstruction in a general population: European Respiratory Society vs American Thoracic Society definition. Chest. 2000;117(5_suppl_2):339S-345S.

23. Sapey E, Ahmad A, Bayley D, et al. Imbalances between interleukin-1 and tumor necrosis factor agonists and antagonists in stable COPD. J Clin Immunol. 2009;29(4):508-516.

24. Hammad DR, Elgazzar AG, Essawy TS, El Sameie SA. Evaluation of serum interleukin-1 beta as an inflammatory marker in COPD patients. Egypt J Chest Dis Tuberc. 2015;64(2):347-352.

25. Hegab AE, Sakamoto T, Saitoh W, et al. Polymorphisms of TNF $\alpha$, IL1 $\beta$, and IL1RN genes in chronic obstructive pulmonary disease. Biochem Biophys Res Commun. 2005;329(4):1246-1252.

26. DeBoer MD, Scarlett JM, Levasseur PR, Grant WF, Marks DL. Administration of IL-1 $\beta$ to the 4 th ventricle causes anorexia that is blocked by agouti-related peptide and that coincides with activation of tyrosine-hydroxylase neurons in the nucleus of the solitary tract. Peptides. 2009;30(2):210-218.

27. Mantovani G, Maccio A, Lai P, Massa E, Ghiani M, Santona MC. Cytokine activity in cancer-related anorexia/cachexia: role of megestrol acetate and medroxyprogesterone acetate. Semin Oncol. 1998;25(2 suppl 6):45-52.

28. Tholstrup T, Raff M, Straarup EM, Lund P, Basu S, Bruun JM. An oil mixture with trans-10, cis-12 conjugated linoleic acid increases markers of inflammation and in vivo lipid peroxidation compared with cis-9, trans-11 conjugated linoleic acid in postmenopausal women. J Nutr. 2008;138(8):1445-1451.

29. Raff M, Tholstrup T, Basu S, Nonboe P, Sørensen MT, Straarup EM. A diet rich in conjugated linoleic acid and butter increases lipid peroxidation but does not affect atherosclerotic, inflammatory, or diabetic risk markers in healthy young men. $J$ Nutr. 2008;138(3):509-514.

30. Wendell SG, Baffi C, Holguin F. Fatty acids, inflammation, and asthma. J Allergy Clin Immunol. 2014;133(5):1255-1264.

31. Kelly GS. Conjugated linoleic acid: a review. Altern Med Rev. 2001; 6(4):367-382.

32. Tavakkoli Darestani A, Hosseinpanah FA, Tahbaz F, Amiri ZO, Tavakkoli Darestani R, Hedayati M. Effects of conjugated linoleic acid supplementation on body composition and leptin concentration in post-menopausal women. IJEM. 2010;12(1):48-59.

33. Zambell KL, Keim NL, Van Loan MD, et al. Conjugated linoleic acid supplementation in humans: effects on body composition and energy expenditure. Lipids. 2000;35(7):777-782.

34. Goncalves CG, Ramos EJ, Romanova IV, Suzuki S, Chen C, Meguid MM. Omega-3 fatty acids improve appetite in cancer anorexia, but tumor resecting restores it. Surgery. 2006;139(2):202-208.

35. Ziegler RG. A review of epidemiologic evidence that carotenoids reduce the risk of cancer. $J$ Nutr. 1989;119(1):116-122.

36. Matin S. The effects of conjugated linoleic acid supplementation on nutritional status, and oxidative stress in COPD patients. [Internal Medicine speciality thesis]. Ardabil University of Medical Sciences, Ardabil, Iran; 2015.

37. Wilson MM, Thomas DR, Rubenstein LZ, et al. Appetite assessment: simple appetite questionnaire predicts weight loss in communitydwelling adults and nursing home residents. Am J Clin Nutr. 2005;82(5): 1074-1081. 
International Journal of COPD

Dovepress

\section{Publish your work in this journal}

The International Journal of COPD is an international, peer-reviewed journal of therapeutics and pharmacology focusing on concise rapid reporting of clinical studies and reviews in COPD. Special focus is given to the pathophysiological processes underlying the disease, intervention programs, patient focused education, and self management protocols.

This journal is indexed on PubMed Central, MedLine and CAS. The manuscript management system is completely online and includes a very quick and fair peer-review system, which is all easy to use. Visit http://www.dovepress.com/testimonials.php to read real quotes from published authors.

Submit your manuscript here: http://www.dovepress.com/international-journal-of-chronic-obstructive-pulmonary-disease-journal 